\title{
Experiências do passado, discussões do presente: a Biblioteca Escolar Infantil do Instituto de Educação Caetano de Campos (1936-1966)
}

Diana Vidal Gonçalves

Doutorado em Educação pela USP. Professora Titular em História da Educação na Faculdade de Educação da USP.

http://dx.doi.org/10.1590/1981-5344/2275

A partir do estudo de caso sobre as práticas instauradas na Biblioteca Escolar Infantil do Instituto de Educação Caetano de Campos, entre 1936 e 1966, durante a gestão da professora-bibliotecária Iracema Marques da Silveira e de alunos-bibliotecários, pretendo interrogar acerca do lugar social, atuação política e estratégias de mobilização cultural das bibliotecas infantis e escolares, estabelecendo um diálogo passado e presente, constituído pela (des)continuidade de ações e propostas. Para tanto, o texto está organizado em três partes. Na primeira, aborda a disseminação de bibliotecas infantis públicas e escolares nos anos 1930 como recurso para promoção da leitura. A seguir, detém-se na experiência realizada na Escola Caetano de Campos. Por fim, traça alguns comentários a título de problematização.

Palavras-chave: Biblioteca escolar. Escola nova. Cultura escolar. Infância.

\section{Past experiences, present debate: the Child School Library of Institute of Education Caetano de Campos (1936- 1966)}

The article presents a case study of school practices of Child School Library of Institute of Education Caetano de Campos, between 1936 and 1966, under the administration of teacher-librarian Iracema Marques da Silveira and her students-librarians. It aims to understand the social place, political acting and cultural strategies of 
child and school libraries, regarding present and past in theirs (dis)continuity. To do so, the article is structured into three parts. The first one is about the spread of public child and school libraries in the 1930s as a way to promote reading. The second is a narrative of Institute of Education Caetano de Campos experience. The last part sketches some comments in order to instate a discussion.

Keywords: School Library. Progressive education. School culture. Childhood.

\section{Experiências do passado, discussões do presente: a Biblioteca Escolar Infantil do Instituto de Educação Caetano de Campos (1936-1966)}

É instigante considerar a pertinência de uma mesa sobre a história das bibliotecas públicas em um Seminário dedicado a debater o "lugar social, atuação política e estratégias de mobilização cultural das bibliotecas públicas no século XXI". Qual o propósito de estabelecer este diálogo passado e presente que se inscreve no subtítulo "velhos problemas, novas realidades"? Por certo, nos canteiros da história, há muito abandonamos a ideia de que o ontem pode legar ao hoje uma fórmula de sucesso a ser recuperada. Não é com esta indagação que voltamos nosso olhar às práticas pretéritas. Se o fazemos é pela oportunidade que lançam de perceber o presente na relação (des)contínua com o passado. O que conservamos? O que alteramos? Como alteramos? A resposta, sempre provisória, a estas questões nos permite acompanhar os processos como fomos reconstruindo nossa experiência, reinventando nosso presente e ressignificando nosso passado.

Ao tomar a Biblioteca Escolar Infantil do Instituto de Educação Caetano de Campos, em São Paulo, e o período entre 1936 a 1966, que coincide com a atuação da professora Iracema Marques da Silveira como bibliotecária, como objeto deste artigo almejo iluminar um caso exemplar, cuja análise pode alimentar questões atuais, mobilizando nossa reflexão sobre a relação entre biblioteca pública e espaço escolar. aspectos:

A exemplaridade desta Biblioteca Infantil se assenta em cinco

(1) Inicialmente, é importante ter em conta que ela surgiu em uma instituição que se pretendia modelar à educação paulista. O Instituto de Educação Caetano de Campos foi criado, em 1933, no âmbito de uma reforma educacional escolanovista, efetuada por Fernando de Azevedo em São Paulo, e embalado pelos preceitos constantes no Manifesto aos Pioneiros da Educação, publicado em 1932. Naquele momento, uma parcela dos educadores nacionais combatia pela elevação da formação do magistério em nível superior, com uma Escola de Professores, antecedida 
pela frequência ao ensino secundário. Esta não era a regra vigente. As Escolas Normais sucediam o ensino primário, implicando um preparo para a docência em nível médio. Não que não houvesse anteriormente outras tentativas de constituir uma Escola Normal Superior em São Paulo, mas o intento não havia logrado êxito.

Nesse sentido, o Instituto de Educação nascia com uma nova missão, com correspondentes apenas no Rio de Janeiro, também Instituto de Educação, ou em Minas Gerais, na Escola de Aperfeiçoamento. Trazia uma composição institucional também nova, similar à do Rio de Janeiro, representada pela articulação entre o Jardim de Infância, a Escola Primária, a Escola Secundária e a Escola de Professores em um mesmo complexo.

(2) Além disso, o Instituto paulista foi o primeiro a ser associado a uma Universidade, como preceituava o Manifesto de 1932. Em 1934, com a criação da Universidade de São Paulo, foi a ela integrado oferecendo não só uma formação superior, mas universitária. Essa integração permaneceu até 1938, quando o Instituto de Educação foi desligado da USP, no calor da disputa entre pioneiros e católicos pelo controle do Ministério da Educação, durante Estado Novo.

(3) Animava essas iniciativas um ideário baseado em preceitos da Escola Nova, em particular da escola e do ensino ativos, em que o protagonismo infantil era preconizado, tanto nas atividades de sala de aula quanto fora, no espaço da escola ou no espaço social. Havia ali a defesa de uma proposta de educação escolar que imbricava escola e sociedade e que, nos anos 1930, foi tornada elemento de discórdia entre grupos que disputavam a orientação nacional do ensino no Brasil.

A Biblioteca Infantil não nasceu nesse ambiente. Sua origem é anterior. Foi criada em 28 de maio de 1925, por iniciativa do professor Carlos Alberto Gomes Cardim, então diretor da Escola Normal da capital, com o auxílio dos professores João Batista de Brito e Renato Braga. Sua organização ficou inicialmente a cargo da professora Dulce Bressane, até agosto de 1927, quando passou aos cuidados da professora Nísia Pereira Bueno, até 1929, momento em que a Biblioteca foi fechada e seus livros recolhidos à Biblioteca do Curso Normal.

(4) No entanto, sua reabertura em 1933, sob a direção da professora Lenyra Fracarolli, logo substituída pela professora Dijorah Carvalho dos Santos que ficou no cargo até 1935, emergiu no novo cenário descrito anteriormente. A intenção de torná-la exemplar se manifestava por sua instalação em 1936 no terceiro andar (recéminaugurado) do prédio na Praça da República, já sob os cuidados de Iracema Marques da Silveira, que permaneceria no cargo de professorabibliotecária até a aposentadoria em 1966. E justamente porque, desde o início desta experiência ela se pretendia modelar e se inseria em um campo de disputa, foi amplamente registrada.

(5) Dois álbuns fotográficos, localizáveis no acervo da Caetano de Campos, narram as atividades realizadas pela professora-bibliotecária e 
pelos alunos-bibliotecários nesses 30 anos; bem como detêm-se na prática de produção do jornal escolar Nosso esforço, inaugurado em 1936.

O que a análise desse caso particular pode oferecer ao repertório das indagações que fazemos hoje sobre o "lugar social, atuação política e estratégias de mobilização cultural das bibliotecas públicas", em particular infantis e escolares, "no século XXI"? É o que pretendo explorar nos próximos itens. Iniciarei por discorrer sobre a disseminação de bibliotecas infantis públicas e escolares nos anos 1930 como recurso para promoção da leitura. A seguir, me deterei na experiência da Caetano de Campos. Por fim, traçarei alguns comentários a título de problematização.

\section{As bibliotecas infantis e escolares nos anos 1930 e a formação do leitor mirim}

Os anos 1930 inauguraram um período fértil nos canteiros da Biblioteconomia brasileira. Em 1929, foi implantado o Curso de Biblioteconomia no Instituto Mackenzie, em São Paulo. Em 1931, reaberto - Curso da Biblioteca Nacional, extinto em 1922, após 7 anos de funcionamento. Em 1936, criada a Divisão de Bibliotecas da Prefeitura Municipal de São Paulo e a Escola de Biblioteconomia a ela vinculada, que, em 1940, foi transformada, após um ano de inatividade, em Escola de Biblioteconomia anexa à Escola Livre de Sociologia e Política.

Estes são indícios de que um importante debate estava em curso na sociedade sobre a organização de bibliotecas nos estados do Rio de Janeiro e São Paulo (SOUZA, 1990) à época. De fato, no final dos anos 1940, estariam em funcionamento no Brasil cinco cursos na área. Além dos da Biblioteca Nacional (Rio de Janeiro) e da Livre de Sociologia e Política (São Paulo), inauguraram-se os cursos da PUC Campinas, da Escola Universidade Federal do Rio Grande do Sul (Porto Alegre) e do Departamento Municipal de Educação e Cultura (Recife). Nos anos 1950, associaram-se outros cursos nos estados de Minas Gerais, Paraná e Amazonas (SOUZA, 1990, p. 53-54).

Segundo Rubens Borba de Moraes, primeiro diretor da Divisão de Bibliotecas Públicas da Prefeitura de São Paulo, operava-se uma mudança na maneira mesma de se compreender o trabalho do bibliotecário:

Os responsáveis pelas bibliotecas [antigamente] eram nomeados porque gostavam de livros, e eram, geralmente poetas, escritores, etc. e o resultado prático era lamentável... A ideia fundamental da [...] Escola de Biblioteconomia era preparar tecnicamente os bibliotecários. O nosso caso era formar profissionais para Bibliotecas Públicas. Nós dávamos [...] uma grande ênfase às questões técnicas; a catalogação era uma coisa importante, que tinha um desenvolvimento bastante grande; a classificação a mesma coisa. (Entrevista com RUBENS MORAES apud SOUZA, 1990, p. 45) 
A alteração implicava em uma nova concepção de profissional bibliotecário, que insistia na formação técnica. Incidia também sobre as práticas bibliotecais instauradas no Brasil. Não foi à toa que, em 5 de janeiro de 1937, pela Lei 2.839, criou-se o Conselho Bibliotecário e regulou-se o ingresso na carreira de bibliotecário mediante concurso e apresentação de diploma concedido por um Curso de Biblioteconomia. No ano seguinte, em 30 de setembro de 1938, fundou-se a Associação Paulista de Bibliotecas (APB). Rubens Borba de Moraes assumiu como seu primeiro presidente (1939-1944) (VIDAL, 2004, p. 189).

As mudanças efetuadas no campo mais amplo da Biblioteconomia combinavam-se a iniciativas de natureza mais propriamente educacional de grande visibilidade. No Rio de Janeiro, surgiram, em 1932, a Biblioteca Central de Educação (chefiada por Armando de Campos); e, em 1934, da Biblioteca Infantil (dirigida por Cecília Meireles); ambas durante a reforma educacional de Anísio Teixeira. Em São Paulo foram inauguradas, em 1931, a Biblioteca Pedagógica Central (sob responsabilidade de Achiles Raspantini); e, em 1936, a Biblioteca Infantil Municipal (a partir de 1955, denominada Biblioteca Infantil Monteiro Lobato), gerida por Lenyra Fraccaroli até sua aposentadoria em 1961. A primeira foi normatizada pela reforma Lourenço Filho; a segunda pela administração Mario de Andrade do Departamento de Cultura.

A isso se entrelaçavam outras ações mais capilares. A partir de 1928, no Rio de Janeiro, cada escola ficava obrigada a manter duas bibliotecas escolares: uma para alunos e outra para professores. Os acervos deveriam ser inventariados em livro distribuído pela Diretoria Geral de Instrução Pública, aberto, numerado e rubricado pelo inspetor escolar. Trimestralmente, o responsável pelas bibliotecas, geralmente um professor da escola, auxiliado por alunos, tinha por incumbência efetuar uma estatística dos livros de preferência do corpo discente, remetendo à Diretoria o mapa do movimento bibliotecal (VIDAL, 2001, p. 158). No ano seguinte, foi regulamentado o cargo de bibliotecário, exclusivamente para gerenciar o acervo destinado à formação de professores da Escola Normal carioca. As duas diretivas faziam parte da reforma educacional promovida por Fernando de Azevedo, o mesmo educador que iria cinco anos depois implantar o Instituto de Educação em São Paulo.

Em 1929, Amadeu Mendes regulamentou a criação de bibliotecas para professores e alunos nas escolas reunidas e grupos escolares paulistas. Em São Paulo, as bibliotecas escolares infantis chegavam a mais de 440 em 1936. Algumas emprestavam livros para os alunos levarem para casa; outras mantinham uma seção de livros para adultos franqueada à família dos alunos (ANNUARIO, 1937, p. 337-342). O Código de 1933 previa que professores e diretores de escolas se valessem da contribuição de associações de pais e mestres, do auxílio da municipalidade, de doação de livrarias e editora e de festivais para organizar suas bibliotecas escolares. Informava, ainda, que a guarda das bibliotecas seria confiada a alunos escolhidos e a direção entregue a professores ou diretores, responsáveis também ela seleção dos livros. 
Disciplinava, por fim, que o processamento dos livros deveria seguir o sistema instituído na Biblioteca Central de Educação.

Não só se normatizavam os registros bibliotecais nas escolas, criando ou adaptando padrões como se instituíam novas práticas de acesso ao livro e à leitura. No que concerne à primeira questão, nas revistas pedagógicas circulavam orientações ao professores-bibliotecários sobre como catalogar os livros e organizar o catálogo, elaborar estatísticas dos exemplares mais frequentemente consultados e dos livros de preferência das crianças, adquirir livros novos, assinar revistas e procurar obter doações. No que tange ao segundo aspecto, instruíam-se os professores responsáveis pelas bibliotecas e os demais professores da escola em técnicas como leitura e narração de histórias, estimulando o acesso direto ao livro em estantes abertas e ao alcance das crianças, hora livre no dia escolar para ler, preenchimento de ficha de leitura por parte dos alunos e constituição de clubes de leitura. De acordo com Clarice Nunes (1993, p. 101), somente no ano de 1933, o Distrito Federal possuía 98 clubes de leitura nas escolas primárias.

É nessa ambiência que se produziu a experiência levada a efeito na Biblioteca Infantil Caetano de Campos, objeto do próximo item. Como destaca Ana Regina Pinheiro (2008, p. 68), era como "laboratório da escola" que as bibliotecas assumiam um lugar de relevo no discurso educacional da época, contrastando com o que os educadores novos denominavam ironicamente de "cemitério de livros" ao referir-se às bibliotecas do passado.

\section{A Biblioteca Infantil Caetano de Campos}

A reorganização da Biblioteca Infantil, em 1936, trazia como novidades a elaboração de estatutos próprios, sua manutenção pela Associação Auxiliar da Escola e, a partir de julho, a publicação do jornal escolar Nosso esforço, feito e dirigido pelos alunos do curso primário, sob a orientação da professora-bibliotecária Iracema Silveira.

O primeiro artigo do capítulo 1 do Regulamento da Biblioteca Caetano de Campos, de 1943, normatizava as funções da Biblioteca:

A Biblioteca Infantil do Instituto Caetano de Campos é organisação extra-curricular que visa dar aos alunos do Curso Primário oportunidade de: a) praticar a leitura como atividade com fins em si mesma, capaz de dar-Ihes prazer e proveito; b) adquirir o amor dos livros e da leitura; c) alargar o conhecimento escolar com conhecimento suplementar, adquirido em leitura indicada como parte de atividade de classe; d) adquirir critérios fundamentais de crítica que os habilitem a fazer a escolha dos livros que hão de ler, dentro e fora da escola; e) habilitar a ler em voz alta para bons hábitos de califasia e a ouvir a narração feita com fins recreativos e artísticos; f) incentivar aquelas atividades que, além de dar- 
Ihes o gosto da leitura, Ihes desenvolvam correlatamente a capacidade de organisar, cooperar, criar.

De acordo com o mesmo Regulamento, a frequência à Biblioteca estaria permitida aos alunos do Curso Primário (art.3) e franqueada diariamente, dentro e fora do período escolar, também como parte de atividade de classe, segundo horário estabelecido pela Direção da Escola Primária (art.4).

Como já mencionado, tanto o trabalho efetuado na Biblioteca Infantil quanto no jornal escolar foi documentado por práticas de registro escrito e fotográfico. Somente porque esta atividade de documentação foi constante e preservada pelos arquivos escolares é que hoje temos indícios desta experiência. (Quantos projetos são efetuados em nossas escolas na atualidade e que não deixam rastros?)

Além dos Álbuns fotográficos Nosso Esforço e Biblioteca Infantil (1937-1966), no acervo da Biblioteca ainda se encontram a Coleção do jornal Nosso Esforço (de 1936 a 1967); pastas contendo Dossiês didáticos; Livro de Ofícios (de 19 maio 1939 a 11 ago. 1943); Correspondências (décadas de 1930, 1940 e 1950, enviadas e recebidas); partitura do hino Nosso Esforço (música de Frederico de Chiara e letra de Maria José, 1956) e três Livros-caixa (1936-1944; 1944-1952 e 19521967) que mantinham o controle da receita e da despesa da Biblioteca. Como sublinha Pinheiro (2008, p. 72-73), a Biblioteca Infantil da Caetano de Campos era sustentada, em parte, por recursos advindos das famílias de alunos e, inclusive, da venda dos jornais, a partir de 1938, além de doações de professores. Os recursos eram utilizados para compra de livros, material didático e acessórios para a Biblioteca. Também recebia doações de livros de editoras, como a Melhoramentos, Companhia Editora Nacional, Livraria Francisco Alves, Livraria Lealdade, Livraria do Globo, J. de Oliveira Campos e Livraria Acadêmica.

Em 1937, um ano depois de sua reabertura, a Biblioteca comemorava a entrega dos móveis novos, adequados à estatura dos leitores mirins, mandados fazer especialmente no Liceu de Artes e Ofícios. A inauguração foi feita com toda pompa e circunstância. Estavam presentes à solenidade, a professora Iracema Silveira, a Diretora da Escola Primária, entre 1935 e 1948, professora Carolina Ribeiro, e o Diretor do Instituto de Educação, entre 1934 e 1938, professor Fernando de Azevedo. 
Figura 1 - Biblioteca Infantil Caetano de Campos

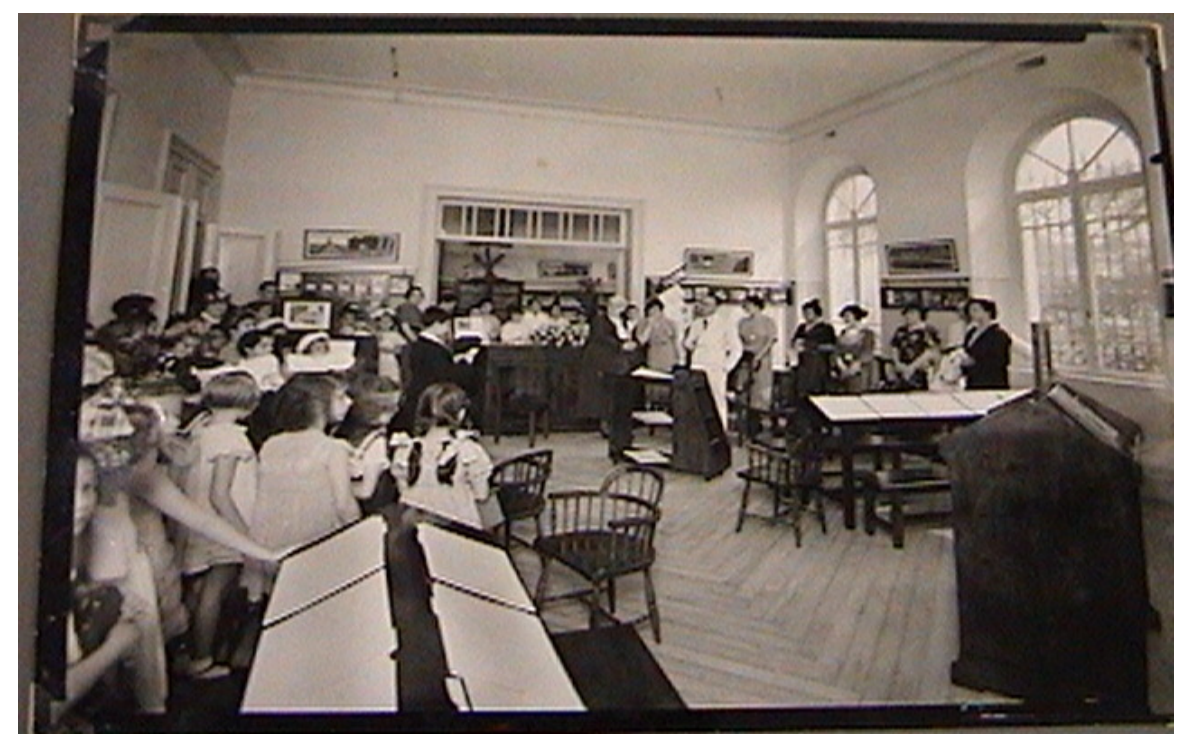

Fonte: Álbum de fotografias da Biblioteca Infantil Caetano de Campos, 19371966.

O ambiente da Biblioteca deveria ser agradável e convidativo à leitura nas suas diferentes formas. Na Figura a seguir, vemos o novo mobiliário sendo utilizado pelos alunos da Escola Primária. Nela se pode notar não apenas as duas modalidades de leitura previstas - alunos sentados em cadeiras diante de mesas ou em pé folheando livros-, mas um conjunto de estímulos oferecidos aos leitores, como livros, quadros e estantes de fácil acesso. A fotografia cumpria a missão de "atestar" que a Biblioteca Infantil correspondia ao que de mais moderno se preconizava no campo educacional. Os alunos apresentavam-se como protagonistas do ato de ler e a escola evidenciava seu acolhimento dos primados escolanovistas (VIDAL, 2000; 2001).

Figura 2 - Biblioteca Infantil Caetano de Campos

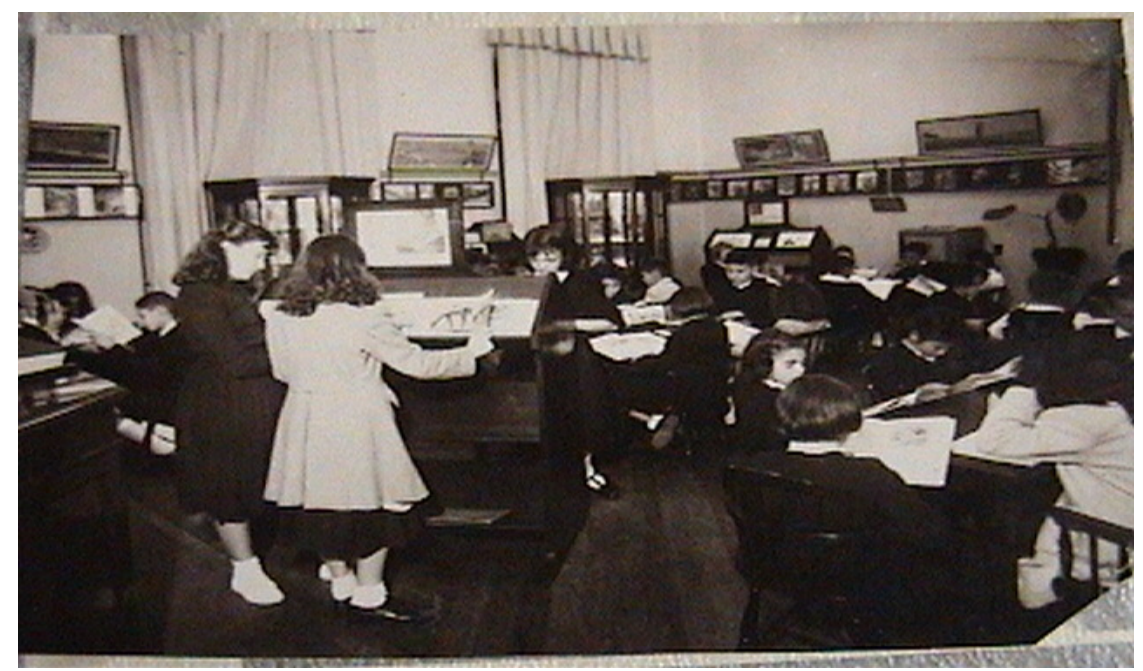

Fonte: Álbum de fotografias da Biblioteca Infantil Caetano de Campos, 1937- 1966 
Compondo este mosaico do ensino e da escola ativos, estava o trabalho dos alunos-bibliotecários. Eram responsáveis pela leitura dos livros novos e sua catalogação através de um sistema criado pela própria bibliotecária, Iracema Silveira, com vistas a facilitar a consulta dos leitores infantis. Tinham também a incumbência de dar atendimento e orientação de leitura aos colegas, além de velar pela correspondência com autores de livros infantis. Esses alunos-bibliotecários eram escolhidos entre os estudantes da $3^{a}$ a $5^{a}$ série do ensino primário que se apresentavam voluntariamente para a atividade, desenvolvida fora do horário de aulas. De acordo com o Regulamento (1943, art. 18)," uma vez escolhidos, os alunos-bibliotecários tomarão o compromisso de um trabalho com horário determinado fora de seu período escolar, segundo a conveniência do trabalho da Biblioteca e a conveniência individual de cada um deles".

Figura 3 - O aluno bibliotecário Joel, atendendo uma colega

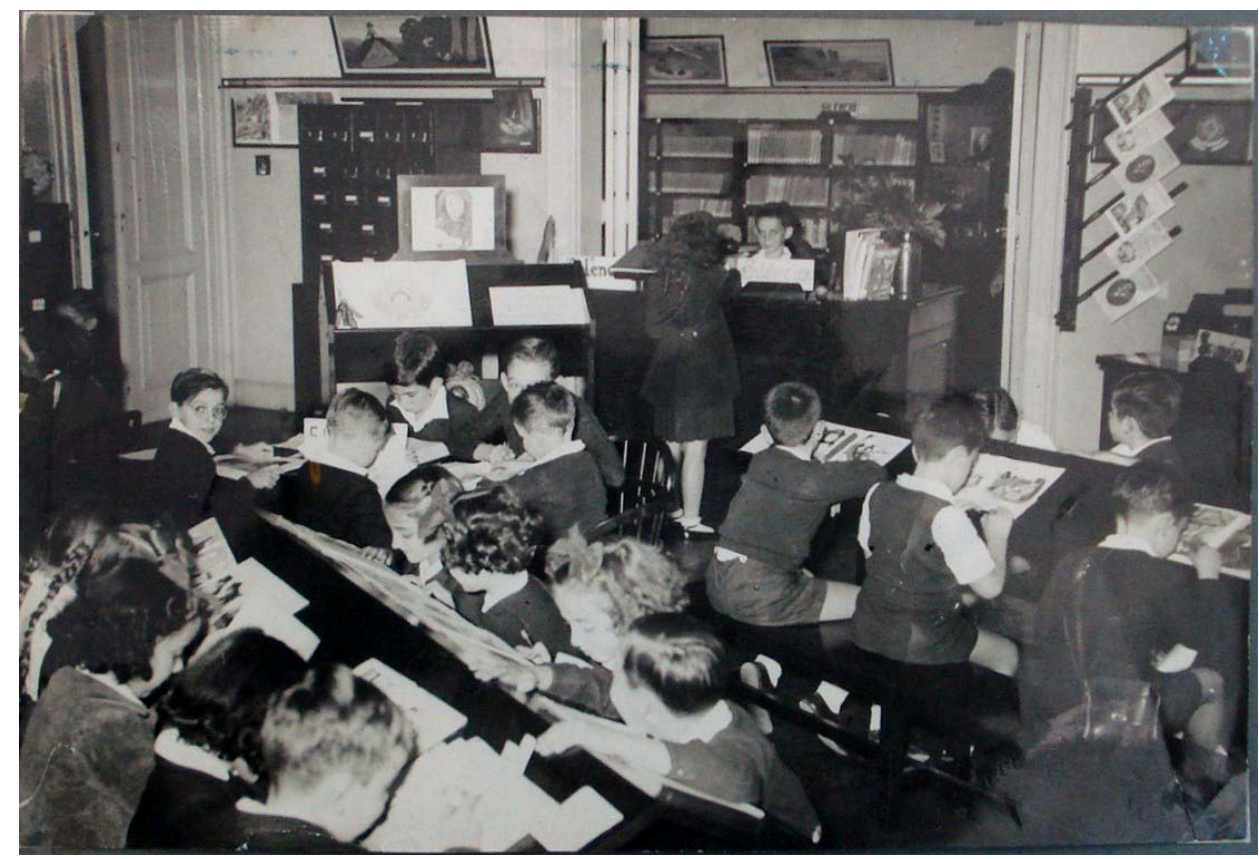

Fonte: Álbum de fotografias da Biblioteca Infantil Caetano de Campos, 1937- 1966 (ABDALA, 2013, p. 141).

De acordo com Iracema Silveira,

[...] As bibliotecas infantis são campo fértil para a aprendizagem da iniciativa livre e da responsabilidade consciente. Nelas, as atividades de catalogação, fichamento, entrega e coleta de livros e arquivamento - são entregues à iniciativa da criança. E, com isto, atinge esta maiores possibilidades de desenvolvimento harmonioso porque é solicitada a maior número de ajustamentos, cada vez mais complexas. É desta natureza, a Biblioteca Infantil Caetano de Campos. Nela, o adulto é o mero coordenador das atividades infantis. Nunca é o instrutor frio; o dogmatizador rígido; o fiscal impertinente [...] (BIBLIOTECA, 1942 apud PINHEIRO, 2008, p. 74). 
Supervisionados pela bibliotecária, os alunos-bibliotecários constituíam também o corpo editorial do Nosso esforço, publicado mensalmente desde sua criação, como flagrado pela Figura a seguir. O exercício permitia ainda o desenvolvimento da capacidade redatora dos alunos e familiarizava-os com outras práticas de escrita, como a máquina de escrever. O trabalho jornalístico incluía, dentre outros, o relato dos eventos escolares, efemérides e datas comemorativas; bem como publicação de textos em auxílio às tarefas escolares, contos, poesia, charadas, indicações de leitura, reportagens sobre escritores de livros infantis e fotografias.

Figura 4 - 1942 Maria Cleo, Maria Zuleika, Flávio e Benedito fazendo a revisão de provas de Nosso Esforço

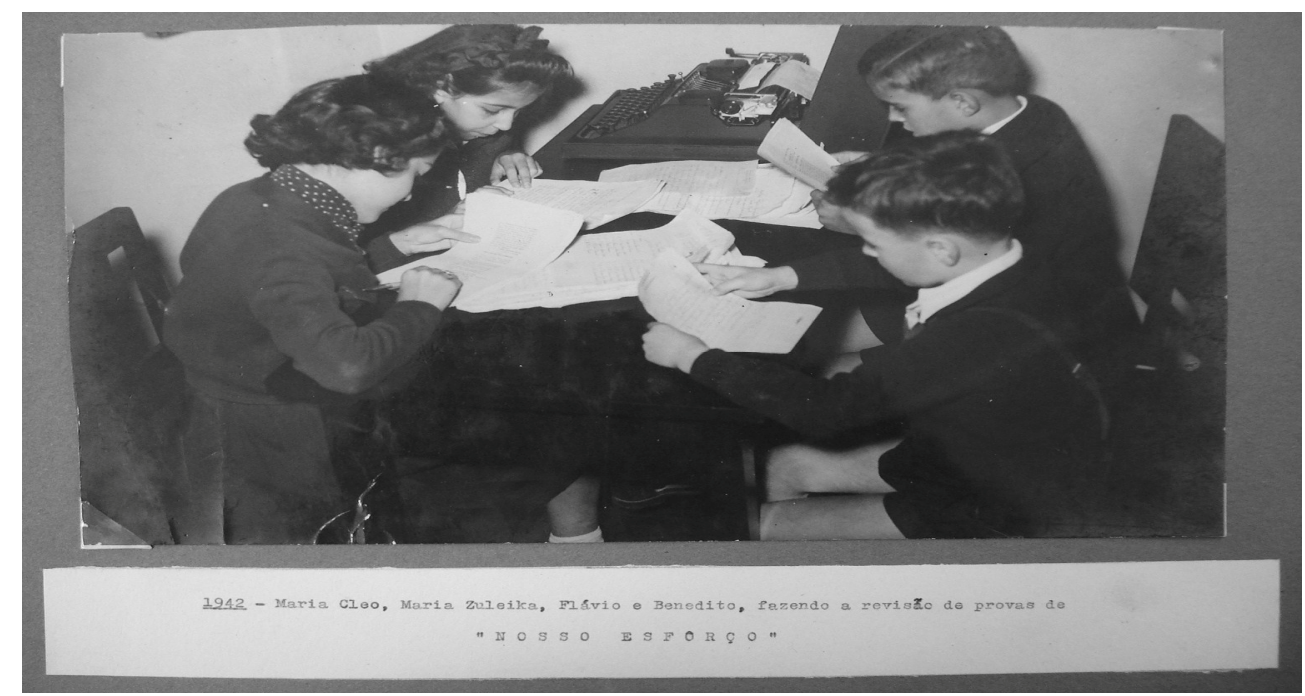

Fonte: Álbum de fotografias do Jornal Nosso Nosso Esforço(ABDALA, 2013, p. 139).

A longevidade do jornal escolar coincidiu com a atuação de Iracema Silveira na biblioteca, o que indica sua participação ativa no fomento das práticas associadas ao espaço bibliotecal e destaca a importância do exercício associado de professores e alunos no universo escolar. O Nosso Esforço passou por várias fases e foi se consolidando em termos formais e materiais, como se pode perceber na imagem abaixo, que reúne os primeiros exemplares feitos artesanalmente e a versão impressa em gráfica a partir de 1940. Além de vendido, era também oferecido em permuta a instituições como o Diretório Regional de Geografia de São Paulo (IBGE) e o Instituto Nacional de Estudos Pedagógicos (INEP) (PINHEIRO, 2008, p. 68). 
Figura 5 - Jornal Nosso Esforço

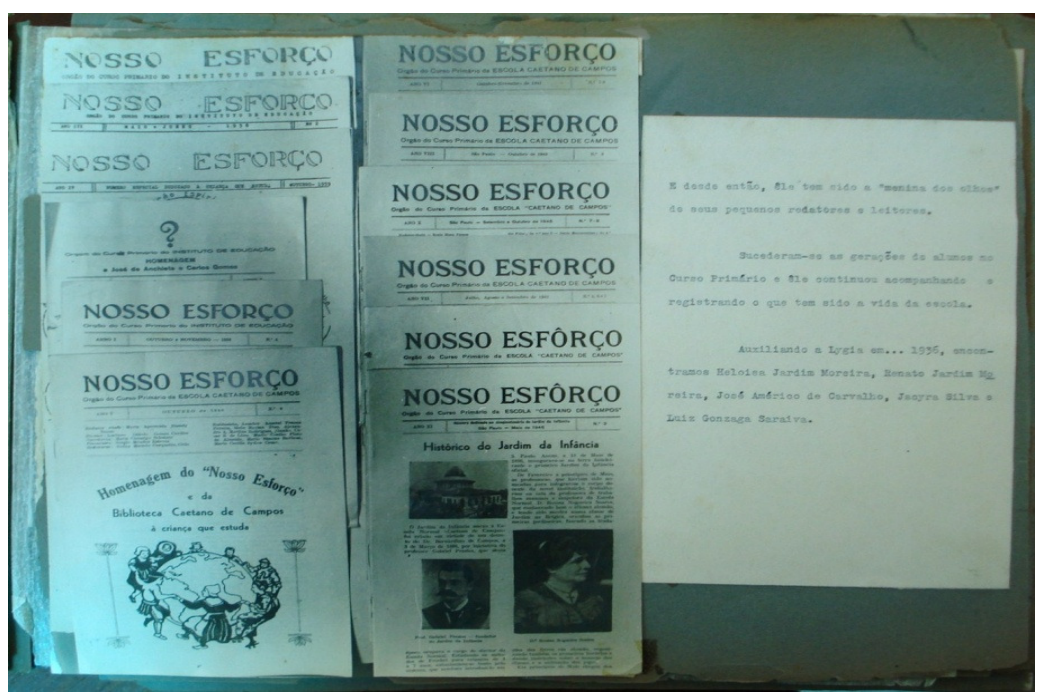

Fonte: Álbum de fotografias do Jornal Nosso Esforço (ABDALA, 2013, p. 288)

Com os objetivos de incentivo ao gosto da leitura, despertar a curiosidade pelos livros, enriquecer o vocabulário infantil, estabelecer contato entre os autores de livros infantis e as crianças e estreitar os laços entre a bibliotecária e os alunos, era realizada na Biblioteca Infantil a "hora do conto". Autores convidados ou a bibliotecária narravam histórias, que os alunos eram estimulados a dramatizar, contando com o auxílio ou não da professora da classe. Incluído no quadriculado do horário da escola primária, o tempo de biblioteca assegurava a cada classe a frequência semanal ao acervo e a participação nas atividades previstas por Iracema Silveira.

Figura 6 - Hora da leitura na Biblioteca Infantil da Escola Caetano de Campos [1940]

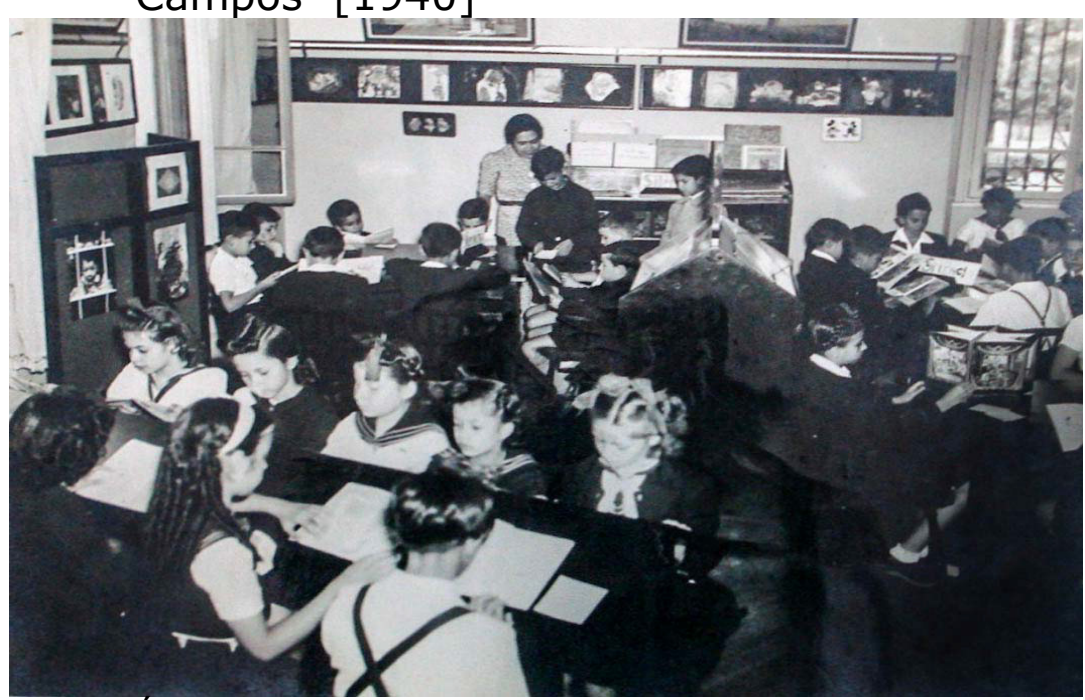

Fonte: Álbum de fotografias do Jornal Nosso Esforço (ABDALA,

2013, p. 140). Essa figura é acompanhada da seguinte legenda: "Que

agradável! Hora de leitura. Ao lado de D. Iracema, os alunos bibliotecários

- Mário e Raul".

Após a leitura, os alunos eram instados a preencher uma ficha, contendo as seguintes informações: nome da obra, nome do autor, data 
do início da leitura, data do término da leitura, Conhece outras obras do mesmo autor? Quais? Que achou do livro, é realidade ou ficção? Que mais o impressionou? Por quê? No verso da ficha, o leitor deveria fazer uma espécie de sinopse do livro. Capeadas e arquivadas, as fichas compunham um importante repertório das formas de ler $e$ interpretar o lido no período.

Só para se ter uma ideia da consulta, apenas no mês de outubro de 1942, foram pedidos 2.073 livros e lidos 1.528. Dentre os autores nacionais preferidos pelas crianças e apurados nos relatórios estatísticos mensais elaborados pela bibliotecária, estavam Ofélia e Narbal Fontes, Monteiro Lobato, Maria Alves Veloso, Viriato Correia, Thales de Andrade e Alaíde Lisboa de Oliveira. Nesse ano de 1942, a Biblioteca Infantil contava com um acervo de 2.523 volumes, dos quais 979 títulos eram de literatura infantil, 474 de uso didático, contendo duplicatas e revistas. Esse acervo atingiria, em 1966, 7.742 volumes. Compunha-se também de Dossiês didáticos produzidos a pedido de professores sobre temas abordados em sala de aula e objeto de pesquisas escolares. Arquivados alfabeticamente versavam sobre tópicas de História, Geografia, Biologia, dentre outras, bem como sobre autores de livros, personagens ilustres e professores da casa, num total aproximado de 800 pastas.

A Biblioteca Infantil acolhia ainda o museu escolar e, a partir de 1943, as seções de discoteca e filmoteca. Congregando todos esses materiais pedagógicos, a biblioteca ampliava sua função de emuladora de práticas escolares. Constituía-se no que anos mais tarde, na década de 1970, emergiu na França, proclamada como grande inovação pedagógica, a $\mathrm{BCD}$ - Bibliothèque Centre Documentaire (Biblioteca Centro Documental) (VIOLET, 1988).

Figura 7 - Museu Pedagógico da Escola Caetano de Campos. "Brazil riquezas naturais, usos e costumes - Seção de História e Ciências Naturais"

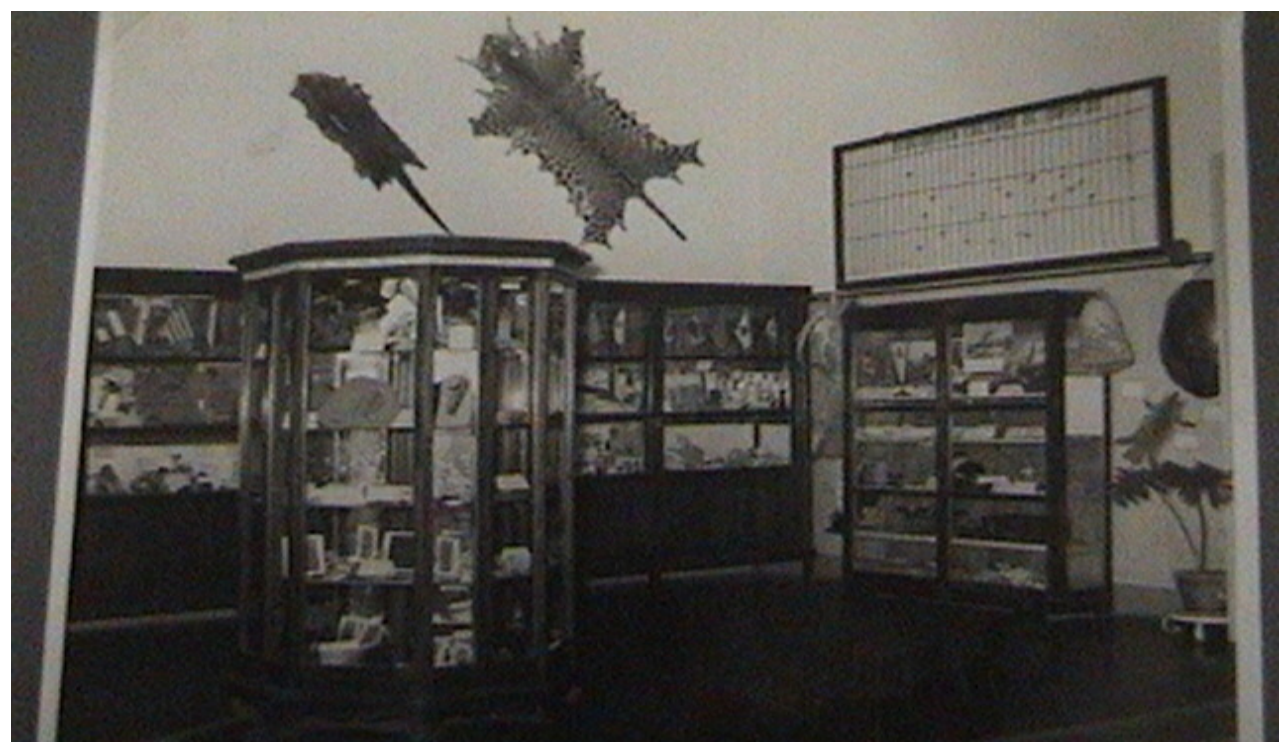

Fonte: Álbum de fotografias da Biblioteca Infantil Caetano de Campos (ABDALA, 2013, p. 66). 
A extensa atividade da biblioteca escolar não seria possível se a ela não fossem conferidos materiais específicos (móveis, livros, revistas), mas, principalmente, se não fosse no seu interior desenhada uma nova relação entre professor e aluno, uma relação pedagógica centrada na leitura e no cuidado dos livros; bem como não fossem delegados à biblioteca um espaço próprio (a sala de biblioteca) no interior do prédio escolar, um tempo determinado (a aula de biblioteca) na grade curricular e aos aluno-bibliotecário e à professora-bibliotecária autonomia de gestão, inclusive de recursos.

\section{Considerações finais}

Apesar de exemplares, as experiências levadas a efeito na Biblioteca Infantil Caetano de Campos não foram únicas. No mesmo período, a biblioteca da Escola Primária do Instituto de Educação do Rio de Janeiro, que havia sido criada em 1932, apresentava características similares. Era também administrada por uma professora-bibliotecária, que tinha por atribuição, além de desenvolver o gosto pela leitura e o amor ao livro, fazer a estatística dos livros lidos, organizar o catálogo, cuidar da política de compra e doação de exemplares, sempre ajudada por "alunosauxiliares que se incumbam de todos os serviços ao seu alcance, sem prejuízo dos trabalhos de classe e de modo que tais funções sejam para eles verdadeiramente educativas" (PROGRAMA..., 1934, p. 180-181).

Maria Violeta Vilas Boas, professora responsável pelo trabalho na biblioteca escolar do Instituto de Educação carioca, assim rememorava sua prática:

Estou mais lembrada do trabalho de [19]35... Levar as crianças a ler histórias para se acostumar a ler compreensivamente, formar o hábito de ler e ser capazes de narrar história. [...] Eu não alfabetizava [...] Quando as crianças chegavam e perguntavam 'o que vamos fazer?' Eu dizia 'olha, hoje, eu pensei de lermos ou livro tal' , ou pedia sugestões. Às vezes, um deles lia para os outros em voz alta. Compreendeu? Aí, 'olha, quem não entendeu, pergunta' ou 'se você achar alguma coisa gozada, comenta'. Quer dizer. Eu fazia eles participarem da leitura. Ou, cada um lendo o seu livro. Ou, frequentemente, lendo por grupos. E, às vezes, um lendo para todos. Ou, então, contando histórias. Contavam histórias. Liam histórias. Inventavam histórias. Às vezes, eu inventava, eles continuavam (Entrevista realizada com MARIA VIOLETA VILAS BOAS apud VIDAL, 2004, p. 194).

Por que experiências como estas narradas para São Paulo ou apenas mencionadas para o Rio de Janeiro não se estenderam a todas as escolas nas décadas seguintes, posto que a regras gerais já se haviam estabelecido? 
Os antigos alunos da Escola Primária Caetano de Campos lembram com carinho de Iracema Silveira. Em 30 anos como professorabibliotecária na instituição, teve contato com estudantes de diferentes idades, acompanhando-os em suas tarefas escolares e ocupando-se em disseminar o prazer de ler (para fruição e estudo). Teria sido ela responsável por despertar o gosto pela leitura (temática recorrente no debate educacional) nessas gerações?

A resposta a estas questões não é simples. Escolas modelares, tanto a Caetano de Campos, quanto o Instituto de Educação do Rio de Janeiro, por muitos anos reuniram um corpo docente e discente selecionado, com forte homogeneidade cultural. Desenvolveram projetos piloto com condições de trabalho diferenciadas de outras escolas da rede pública. 0 que o estudo desses casos, então, podem nos auxiliar hoje, quando escola se afirma como inclusiva e multicultural?

Por um lado, é preciso reconhecer que, atualmente, os investimentos públicos em bibliotecas escolares têm sido canalizados majoritariamente para a distribuição de livros às escolas, frequentemente desconsiderando o provimento de instalações adequadas à conservação do acervo e à leitura (espaço e mobiliário específico para a biblioteca), a inclusão de frequência à biblioteca no quadro de horários (tempo determinado institucionalmente) e a autonomia da administração, guarda e uso do acervo pela comunidade escolar.

A ação específica de formação de professores-bibliotecários e o envolvimento de alunos com o processo mesmo de gestão da biblioteca e de promoção da leitura são temas ainda pouco abordados. Como resultante, em boa parte das escolas públicas, a biblioteca escolar apresenta-se como um depósito de livros, por vezes constantemente fechada; por vezes utilizada como um recurso insurgente para cobrir "hora vaga", sem programação específica ou exercício didático complementar ao trabalho em sala de aula.

Por outro lado, ao tomar a Biblioteca Infantil Caetano de Campos entre 1936 e 1966 como objeto, não pretendi oferecer um modelo a ser copiado, mas suscitar a reflexão. O relato evidencia que muitas das práticas intentadas nos anos 1930 ainda fazem parte do repertório de recomendações para a iniciação leitora, como a hora conto ou a "contação" de história. Outras, entretanto, parecem ter ficado esquecidas, como a preocupação em estimular o prazer da leitura tanto para a fruição quanto para o estudo das disciplinas, o trabalho intelectual.

Mas, especialmente, creio que a narrativa nos incita a perceber que alterações nas práticas escolares só conseguem ser implementadas quando atuamos simultaneamente sobre os três principais eixos da cultura escolar, quais sejam: espaço, tempo e relações intersubjetivas. Nesse sentido, para além de ampliar o acervo de impressos (e atualmente de acesso ao conteúdo digital) nas bibliotecas escolares, é imprescindível criar um ambiente bibliotecal acolhedor e confortável; inserir o tempo de biblioteca na grade das atividades escolares regulares, associada a um trabalho pedagógico sistemático e prestigiado no universo da escola; e, 
por fim, implicar a comunidade escolar (o que inclui as famílias) com o exercício bibliotecal, seja na disponibilização do acervo, seja na construção de suas estratégias de conformação e guarda.

Afinal, se a escola hoje é multicultural e inclusiva, não há lugar mais apropriado para o exercício desses primados que a biblioteca, espaço multidisciplinar e multicultural por excelência.

\section{Referências}

ABDALA, Rachel Duarte. Fotografias escolares: práticas do olhar e representações sociais nos álbuns fotográficos da Escola Caetano de Campos (1895-1966). 2013. Tese (Doutorado em Educação)-Faculdade de Educação, Universidade de São Paulo, São Paulo, 2013.

ANNUARIO DO ENSINO DO ESTADO DE SÃO PAULO (1935-1936). São Paulo: Tipografia Siqueira, 1937.

BIBLIOTECA INFANTIL CAETANO DE CAMPOS. Álbum de fotografias da Biblioteca Infantil Caetano de Campos, 1937-1966.

BIBLIOTECA INFANTIL CAETANO DE CAMPOS. Álbum de fotografias do jornal Nosso Esforço, 1936 a 1967.

NUNES, Clarice. A escola redescobre a cidade: reinterpretação da modernidade pedagógica no espaço urbano carioca (1910-1935). Tese (Concurso para Professor Titular em História da Educação do Departamento de Fundamentos Pedagógicos da ESE/UFF)-Universidade Federal Fluminense, Niterói, 1993.

PINHEIRO, Ana Regina. Escola "Caetano de Campos": escola paulista, escola vanguardeira. Doutorado: Faculdade de Educação, UNICAMP, 2008.

PROGRAMA DE CIÊNCIAS SOCIAIS. Departamento de Educação do Distrito Federal. Programas e guias de ensino, Série C, n. 4 A, v. 2, Edição Preliminar. Rio de Janeiro: Editora Nacional, 1934.

BIBLIOTECA INFANTIL CAETANO DE CAMPOS. Regulamento da Biblioteca Infantil "Caetano de Campos". São Paulo, 1943.

SOUZA, Francisco das Chagas de. O ensino da Biblioteconomia no contexto brasileiro. Florianópolis: Ed. UFSC, 1990.

VIDAL, Diana Gonçalves. Livros por toda a parte: o ensino ativo e a racionalização da leitura nos anos 1920-1930 no Brasil. In: ABREU, Márcia. (Org.). Leitura, história e história da leitura. Campinas; São Paulo: Mercado das Letras/ FAPESP, 2000. p. 335-355.

VIDAL, Diana Gonçalves. O exercício disciplinado do olhar: livros, leituras e práticas de formação docente no Instituto de Educação do Distrito Federal (1932-1937). Bragança Paulista: EDUSF, 2001.

VIDAL, Diana Gonçalves. Bibliotecas escolares: experiências escolanovistas nos anos 1920-1930. In: MENEZES, Maria Cristina. (Org.). 
Educação, memória, história: possibilidades, leituras. Campinas: Mercado de Letras, 2004. p. 187-212.

VIOLET, Michel. Le concept de BCD. Association Française pour la Lecture. Les actes de Lectures, n. 24, p. 1-7, déc. 1988. 